\title{
INJUSTIÇA AMBIENTAL, MEIO AMBIENTE E VULNERABILIDADE: PROBLEMATIZANDO A CONSTRUCÃO SOCIAL DA DESTERRITORIALIZAÇÃO DE COMUNIDADES POBRES, ÉTNICAS E NEGRAS
}

Tarcisio Augusto Alves Silva*

RESUMO: O presente trabalho pretende articular as categorias injustiça ambiental, meio ambiente e vulnerabilidade, para problematizar a construção social da desterritorialização de comunidades pobres, étnicas e negras. O objetivo, portanto, é refletir sobre o lugar dessas populações no modelo de desenvolvimento hegemônico, contemporâneo, e dos processos mobilizatórios de enfrentamento a vulnerabilidade e desterritorialização provocados por seus impactos.

PALAVRAS-CHAVE: Desterritorialização; Injustiça ambiental; Vulnerabilidade social.

\section{ENVIRONMENTAL INJUSTICE, ENVIRONMENT AND VULNERABILIT Y: PROBLEMATIZING THE SOCIAL CONSTRUCTION OF DE-TERRITORIALIZATION OF POOR, ETHNIC AND NEGRO COMMUNITIES}

\begin{abstract}
Current analysis defines environmental injustice, environment and vulnerability to problematize the social construction of de-territorialization of poor, ethnic and Negro communities. The rank of these populations within the model of hegemonic and contemporary model is discussed, coupled to the challenging processes against vulnerability and de-territorialization caused by their impacts.
\end{abstract}

KEY WORDS: De-territorialization; Environmental injustice; Social vulnerability.

Doutor em Sociologia pela Universidade Federal de Pernambuco (UFPE); Docente adjunto III da Universidade Federal Rural de Pernambuco (UFRPE), Pernambuco, Brasil.

E-mail de correspondência: deescada@yahoo.com.br 


\section{INTRODUÇÃO}

As estratégias atuais de desenvolvimento estão alçadas sobre a necessidade constante de tornar a acumulação do capital e a elevação de sua taxa de lucro uma condição permanente, seja em territórios em que tradicionalmente sua exploração se mantém há séculos, seja em regiões de recente interesse da produção capitalista. Sob esta ótica, tem-se historicamente praticado o genocídio, o extermínio, a pauperização e a desterritorialização de populações em diversas partes do planeta.

Populações mais sensíveis a essas ações são oriundas de comunidades étnicas, negras, ribeirinhas, de agricultores familiares e de grupos sociais com baixa capacidade de representação política. No Brasil, o desenvolvimento que atinge seus territórios, quase sempre, se vale dos braços do Estado que, capturado pelo mercado e/ou associado ao grande capital, tem promovido as mais diversas formas de injustiça ambiental em nome da geração de empregos, da defesa das commodities agrícolas e minerais e da manutenção das taxas de crescimento econômico.

O lugar, no sentido utilizado por Tuan $(1983)^{2}$, dessas populações é materialmente desconstruído e simbolicamente redefinido por outras lógicas orientadas por tempos (de trabalho orientados pelo mercado) e espaços (associados à produção em escala industrial) que não conferem mais sentido àqueles que preteritamente habitavam o território. Os efeitos de tal processo sobre esses indivíduos se verificam pela desagregação dos laços sociais que compunham as formas de solidariedade grupal, na perda da identidade coletiva e nas formas de violência que se adentram em seu cotidiano. Se observarmos, por exemplo, o caso de muitos povos indígenas o desenvolvimento chega sempre ameaçando a sua integridade física e cultural, seja pela exploração e violência sexual, seja pelas mortes que ocorrem quando estes têm que defender suas terras contra os invasores, ou ainda pela perda dos valores, ritos e traços peculiares de sua cultura. Notadamente esse tipo de violência ocorre como efeito de um processo que envolve a segregação socioespacial de seus territórios e, na mesma intensidade, a desterritorialização como expressão permanente da perda de seu habitat.

Esse desenvolvimento, revestido de progresso, como vem ocorrendo

2 "Os lugares são centros a que atribuímos valor e onde são satisfeitas as necessidades biológicas de comida, água, descanso e procriação” (TUAN, 1983, p. 04). 
em diversas regiões do país, reestabelece antigas práticas de ataque aos direitos humanos a exemplo da servidão por dívida, do trabalho escravo e da exploração sexual de crianças e adolescentes (vinculados à contemporaneidade da precarização do trabalho migrante nas áreas de fronteira agrícola com expansão de monoculturas como a soja e a cana-de-açúcar). Além disso, verifica-se que o alargamento de novos espaços de cultivos (fronteira agrícola) e pastos tem provocado a redução cada vez maior das áreas de preservação e conservação dos biomas florestais brasileiros. Existem, neste sentido, áreas como o Parque Nacional Indígena do Xingu (MT), em que o fenômeno do "abraço da morte"3 compromete a existência de 16 comunidades indígenas devido ao constante desmatamento e devastação ocasionados por queimadas associadas à formação de lavouras e pastagens.

No Nordeste brasileiro não tem sido diferente. Diversos grupos sociais (pescadores, pequenos agricultores familiares, assentados, indígenas e quilombolas) têm perdido seus territórios pressionados pelas políticas energéticas que, ao construírem hidrelétricas e barragens, causam a perda gradual dos estoques de pesca nos rios, mares e oceanos. Portanto, muitas dessas comunidades, ao serem espremidas em áreas de forte especulação imobiliária e espaços focais de atração de investimentos industriais são pressionadas a abandonar seus territórios. Um exemplar desse cenário se encontra em Pernambuco (Brasil) com a expansão do Porto de Suape e pelo crescimento da exploração da carnicicultura na Mata Norte do Estado.

Diante desse quadro, o meio ambiente é tomado como um campo não só de exploração dos recursos ambientais, mas também das populações localizadas nas regiões onde o capital encontra as possibilidades ideais para a sua reprodução. Para fazer-se aceitável, o desenvolvimento que se propõe vem mascarado de um discurso ambiental em que as empresas e o Estado expressam suas intenções de sustentabilidade ambiental, mesmo que na prática se verifique que os caminhos propostos não poupem esforços para que o crescimento da economia se mantenha aos custos do "sacrifício socioambiental".

3 O termo "abraço da morte" refere-se ao estrangulamento, ou pressão exercida pelas áreas de entorno, ao Parque onde a soja tem avançado e destruído a floresta. Ver depoimento de Beto Ricardo em: < http://www. somos1so.com.br/2011/01/18/o-parque-do-xingu-e-o-abraco-da-morte/> . 
O processo de desterritorialização compõe, desse modo, uma das faces do sacrifício socioambiental impondo o deslocamento e desenraizamento dessas populações que são pressionadas pelos impactos provocados pelos empreendimentos ou, de forma compulsória, pela ação do Estado que advoga suas atividades em nome dos benefícios que elas possam trazer a uma sociedade genérica, embora as externalidades negativas sejam sentidas e assumidas apenas pelas populações atingidas.

Éassimque, maisqueem qualqueroutraépoca, omodelode desenvolvimento assumido pelo Brasil, ao afetar e comprometer os recursos ambientais dispostos no meio ambiente, tende a promover a vulnerabilidade social de determinados grupos humanos (pescadores, quilombolas, pequenos agricultores e índios). Nesse trabalho, portanto, procura-se articular as categorias injustiça ambiental, meio ambiente e vulnerabilidade para problematizar a construção da desterritorialização de comunidades pobres, étnicas e negras. O objetivo é refletir sobre o lugar dessas populações no modelo de desenvolvimento hegemônico contemporâneo, a produção de vulnerabilidades e a desterritorialização provocadas por seus impactos.

\section{O TERRITÓRIO E O PROCESSO DE DESTERRITORIALIZAÇÃO}

A construção de um território é entendida como resultante de relações de poder que envolvem grupos sociais na dinâmica e composição de um determinado espaço. Entretanto, a constituição de locais em que a reprodução desses grupos passa a se tecer está alimentada pela demanda por recursos materiais que forneçam amenidades às intempéries que a natureza possa sujeitar os seres humanos.

A noção de território enquanto categoria social se inicia, aqui, pela análise etimológica da palavra que é expressa em terra de pertencimento - terri (terra) e torium (pertencente a) -, do latim (HAESBAERT, 2004). Sob uma perspectiva política o território pode ser analisado pelos limites do Estado-Nação, ou sob uma perspectiva econômica quando se leva em conta a produção, consumo e o campo de atuação de grandes empresas. Quanto aos que procuram enfatizar os aspectos culturais a relevância encontra-se nas qualidades simbólicas e idearias dos grupos 
sociais e, finalmente, aos que se interessam pelos aspectos físicos do território darão maior atenção às questões relacionadas com a utilização dos recursos e à questão ambiental (HAESBAERT, 2004).

Milton Santos (1998) pensa a produção do território como espaço de relações sociais, ao compreendê-lo a partir de diferentes funções espaciais ou pelos seus diferentes usos espaciais. Para ele, portanto, não é possível entender o território ignorando as relações políticas e econômicas que se estabelecem no modelo capitalista de produção. Por isso, o território só se torna um conceito útil se o pensarmos juntamente com aqueles atores que dele se utilizam (SANTOS, 2000, p. 22). Por isso, para Milton Santos, o território, em si, não é uma categoria analítica, o que lhe dá sentido são suas formas de uso revelando assim um território herdado ou um território alienado. O primeiro compreendido "por um contínuo intercâmbio entre mortos e vivos, em que as normas e as regras inscrevem-se na materialidade, orientando a cultura imaterial" (RIBEIRO, 2005, p. 269). O segundo, entendido pela venda do seu patrimônio natural e cultural.

Analisando outra variável de construção do conceito de território encontramos a identidade coletiva, entendida aqui como "uma rede de relacionamentos ativos entre atores que interagem, se comunicam, se influenciam mutuamente, negociam e tomam decisões" (MELUCCI, 1996). Esta comportaria um elenco de aspectos (crenças, valores, comportamentos) capazes de conduzir a respostas, mais ou menos coerentes, sobre o que motiva as populações locais a reagirem contra qualquer prática que por ventura venham a comprometer as lógicas de reprodução de seus indivíduos. Assim, o território entendido enquanto identidade repousaria no compartilhamento de valores comuns, práticas sociais apreendidas na vivência do mundo da vida e no reconhecimento do outro e de si mesmo em um espaço de sociabilidade coletiva (a casa, o trabalho, a religião, etc) em que se estabelecem referências com as quais se ordena o mundo.

A apropriação de um determinado espaço se dá, desse modo, à medida que o indivíduo ou grupo o representa para si e para os outros. "Enquanto espaço da ação, o território passa a ser a mediação entre indivíduos ou grupos. É uma relação triangular, pois a relação com o território é uma relação mediadora da relação entre os sujeitos sociais" (SOUZA; PEDRON, 2007, p. 137). 
A identidade como variável de constituição de um território expressa, assim, uma forma particular de ordenação de parcela do espaço geográfico. Os recursos naturais presentes nele compõem uma das faces da ordenação espacial tecida a partir da constituição de relações sociais específicas. Tais recursos, embora possuindo um caráter de bem difuso, formam um conjunto indispensável de elementos que interagem com a identidade cultural da comunidade de modo que a disponibilidade desses recursos, sua exploração sustentável e a sua preservação podem se tornar parte constitutiva dos traços culturais que dão coesão social às formas de sociabilidade dos indivíduos.

Isto significa que a manutenção e integridade dessa base material é condição sine qua non para reprodução social e continuidade de padrões culturais de sociedades específicas. Com isso, se pode entender que os recursos dispostos na natureza não sejam considerados apenas naturais, mas sociais, pois "se são naturais não são recursos, e para serem recursos têm que ser sociais" (SANTOS, 2000, p. 20).

Essa assertiva propõe que a natureza no processo histórico de constituição das sociedades não pode ser encarada, a não ser de maneira isolada, como natural, mas sim como um valor. "O valor da natureza está relacionado com a escala de valores estabelecida pela sociedade para aqueles bens que antes eram chamados de naturais" (SANTOS, 2000, p. 18).

As implicações desse fato se expressam no entendimento de que, se diferentes sociedades são portadoras de valores e visões de mundo distintas, os usos particularizados desses recursos podem resultar em conflitos quando as práticas sociais de uma população nativa são confrontadas com a presença de novos atores que, ao explorarem em um mesmo território seus elementos, comprometem as possibilidades de reprodução dos primeiros. Este processo, em muitas ocasiões, é indicativo da relação entre verticalidades e horizontalidades, ou seja, resultado das dinâmicas que atendem aos interesses das empresas (em escala mundial) e as formas de solidariedade e resistências presentes nas localidades, conforme descritas por Milton Santos (2001).

Isto resulta que sob a apropriação social do mundo material pelas práticas de grupos com trajetórias sociais e culturais diferenciadas se verificam estruturas desiguais de "acesso, posse e controle de territórios ou de fontes, fluxos e estoques 
de recursos materiais" (ACSELRAD, 2004a, p. 15). A distribuição desigual do poder no campo social torna-se, portanto, um componente expressivo da capacidade de transformação do território e de seus recursos. No caso específico das sociedades modernas, como a mobilidade do capital não se restringe a um espaço local, regional, ou mesmo nacional, seu poder devastador se move para outros espaços deixando para as populações residentes um lastro de destruição e desolação territorial. Isso demonstra que, quando os recursos materiais finitos são explorados sob a ótica utilitarista da economia capitalista, escasseiam-se comprometendo, a curto prazo, os grupos humanos que dependem diretamente de sua manutenção.

Com efeito, a ação de empresas transnacionais tem demonstrado que os limites físicos do planeta não têm sido considerados justamente porque elas buscam com a desesperada necessidade de maior produtividade, "lugares mais apropriados para aumentar o lucro de alguns, em detrimento de outros" (SANTOS, 2000, p. 22).

A história recente tem demonstrado que os custos socioambientais dos interesses por novos locais em que recursos materiais estejam menos escassos, ocorrem em dois movimentos que se manifestam da apropriação de um território. $\mathrm{O}$ primeiro diz respeito à degradação das condições de vida da população que historicamente habitava aquele lugar e, em segundo, a desterritorialização dessas populações expulsando-os do lugar que, ancestralmente, fora ocupado por diversas gerações.

A perda de seu lugar de reprodução social faz com que se promova um processo de marginalização e, também, desterritorialização de comunidades inteiras. Nesse sentido, a desterritorialização é compreendida pela perda de referenciais espaciais, concretos sob o domínio das relações imateriais (HAESBAERT, 2002, p. 56).

A desterritorialização analisada sob o jugo da degradação dos recursos materiais necessários à existência dos padrões sociais reproduzidos por uma população tradicional, por exemplo, revela que esse fenômeno pode ocorrer sem que haja a expulsão dos indivíduos do território. Quando as populações veem o lugar (ou território) em que vivem descaracterizado pelos impactos de novas lógicas produtivas e relações de produção, elas podem se manter no território incorporadas como mão de obra, no entanto, desconectadas das razões e decisões que promovem 
a modificação do espaço. Procede-se, desse modo, uma desterritorialização em que os indivíduos perdem a autonomia sobre o lugar (ou território) e se subordinam à lógica invasiva (da racionalidade dominante), sem que tenham perspectiva de migrar para outra região. No caso de populações pobres que vivem em centro urbanos, ou em região de baixa capacidade para gerar empregos, vê-se, com frequência, nesses casos, uma naturalização dos riscos (LEITE LOPES et al., 2004) pela incorporação passiva dos impactos indesejados mas entendidos como aceitáveis diante de algumas situações de empobrecimento.

Muito mais frequente, entretanto, é a desterritorialização seguida da perda e expulsão do território. Nesse caso, as populações residentes são deliberadamente pressionadas a se retirar do ambiente onde viviam para dar lugar a obras de grande envergadura como hidrelétricas e barragens, ou são compulsoriamente exprimidas em seus espaços pelo avanço de pastagens e áreas de plantio de grandes monoculturas, forçando-os a desocupar seu território pela força das transformações que lhes são impostas pelos interesses privados e pelas políticas do Estado. Das estratégias que orientam estas práticas encontramos desde as insuficientes e retardatárias indenizações pagas pelos governos, ao deslocamento das populações para áreas residenciais construídas em espaços vazios de conexão cultural e identitária. A adaptabilidade dos atores ao novo ambiente é a resposta esperada pelos agentes da desterritorialização (mercado e Estado), embora nem sempre essa ocorra, pois a privação dos indivíduos aos objetos da memória coletiva da comunidade termina frustrando essa intenção. Nesse momento, portanto, a capacidade de resiliência das populações mais pobres é submetida à prova pela produção e exacerbação da pobreza associada aos efeitos de um desenvolvimento autoritário e excludente.

Esse processo coordenado pelo recrudescimento dos efeitos desse modelo de desenvolvimento desconfigura a paisagem local provocando um afastamento dos respectivos espaços de afirmação material e/ou imaterial, funcional e/ou simbólica das populações por ele atingidas. Embora esse fenômeno não seja uma novidade histórica sua atualidade vem se tornando evidente pelas contradições presentes na realização de projetos que caminham na contramão da história. Ou seja, enquanto cada vez mais se tornam claros os sintomas de nossa crise civilizatória, e suas consequências perante a natureza, mais se alimenta um modelo de desenvolvimento 
pautado na exploração dos seres humanos e dos recursos dispostos no meio ambiente.

Neste sentido, a desterritorialização está relacionada à capacidade de empresas, e de parte da sociedade, de estabelecerem novas formas de mobilidade de seus interesses e de suas bases físicas, ao se libertarem dos efeitos das barreiras impostas entre o tempo e o espaço. "Nessa lógica, o grau de sucesso de uma empresa, para citar apenas um exemplo, dependeria mais da respectiva conectividade às redes imateriais de fluxos que da sua localização específica" (FERNANDES, 2008, p. 5). De outro modo, o fenômeno pode ser estudado como um fluxo contínuo da mobilidade de capitais e de empresas com o intuito de explorar áreas promissoras de uma região, impulsionadas, sobretudo, pelos avanços das tecnologias da informação, da desregulamentação de leis trabalhistas, ambientais e da perda do poder exercido pelos Estados-Nação na configuração das relações engendradas a partir das dinâmicas instituídas pelo capital.

$\mathrm{O}$ processo de mobilidade relativo às classes dominantes no contexto da globalização se trata, na verdade, segundo Haesbaert (2004), de uma reterritorialização (fruto da extrema valorização da densidade informacional de alguns pontos altamente estratégicos do espaço) em novas configurações, que o autor prefere tratar utilizando o termo multiterritorialização (resultante da comunicação instantânea da multiplicidade de territórios e sua articulação na forma de territóriosrede) e seus impactos sobre a base física do território.

Haesbaert (2004) propõe com isso que o debate sobre desterritorialização não se restrinja à análise de fenômenos relacionados à hibridização cultural ou à ultravalorização da mobilidade do capital e das empresas, sem considerar que o seu efeito, sob os grupos subalternos, transforma um território de vida em território de precarização imposto com a mobilidade estrutural da produção. Ou seja, há um sintoma desse fenômeno que deve ser analisando sob o enfoque de quem efetivamente vive a desqualificação do lugar (ou território), pela perda do controle físico, pela migração e pela perda de referências simbólicas.

Nesse sentido, a desterritorialização de populações pobres, étnicas, negras, ribeirinhas, de pequenos agricultores, dentre outros, se efetiva no atual modelo hegemônico de desenvolvimento pela possibilidade de vulnerabilização social desses 
grupos ou pela ampliação das suas, já frágeis, condições de existências. Nos dois casos não há como deixar de considerar que a vulnerabilidade destas populações se estabeleça como fruto de decisões econômicas e não pelo resultado de processos naturais. Ainda que provocados por impactos naturais sua existência não perderia, a depender da situação, esse caráter social se na prevenção aos desastres e riscos ambientais as tomadas de decisões não penalizassem com frequência o lado mais frágil da estrutura social, que são estas populações.

É assim que se a desterritorialização é um processo social imposto aos grupos e minorias sociais mais frágeis pelos tomadores de decisão alinhados a uma perspectiva de desenvolvimento econômico excludente, logo, a vulnerabilização a que se veem expostos tais grupos não deve ser encarado de forma natural. Ela resulta da dinâmica perversa de constituição de uma lógica que se envida no desalojamento e expulsão de certa população de seu território de vida. Portanto, "a situação das populações atingidas que, mesmo se não estão em estado de grande pobreza, estão vulnerabilizadas, sem condições de influenciarem nas decisões" (HERCULANO, 2006, p. 3) lhes impõem os custos da migração para novas regiões e áreas urbanas, onde a segregação socioespacial se torna um dos elementos construtores do novo território, instituindo assim um processo de reterritorialização. Todo esse processo é expressão da mais clara forma de injustiça ambiental que orienta os critérios locacionais de grandes empreendimentos e empresas. Por injustiça ambiental compreendemos o fenômeno social em que a crescente escassez de recursos naturais e a desestabilização dos ecossistemas afetam de modo desigual, e muitas vezes injusto, diferentes grupos sociais ou áreas geográficas (ACSELRAD; MELLO; BEZERRA, 2009).

\section{A VULNERABILIDADE ENQUANTO PRODUTO DA DESTERRITORIALIZAÇÃO}

$\mathrm{Na}$ contemporaneidade assistimos à destruição dos recursos ambientais associada a um desenvolvimento desenfreado, a partir de avanços técnicos, da modernização da agricultura, da expansão da industrialização, da urbanização e da metropolização das cidades. Na análise dessa problemática, Porto (2007) considera 
que o tema vulnerabilidade ajuda a desvelar a dimensão social da complexidade na análise e enfrentamento dos riscos ambientais e ocupacionais em países como o Brasil, como também contribui para trazer à tona questões éticas, políticas e técnicas que conformam a distribuição dos riscos nos territórios e a capacidade das populações de enfrentá-los.

Vale ressaltar que, ao se tratar as condições de vulnerabilidade, se evidencia a expressão simultânea da liberdade humana e de seu abuso, de forma que, como nos alerta Porto (2007, p. 158), "ela deriva das opções de desenvolvimento econômico e tecnológico, do poder exercido pelos seres humanos sobre outros ou sobre o funcionamento da natureza, que reage e intervém nos ciclos da vida humana e não humana".

Outro aspecto a considerar de acordo com esse autor (2007) é que campos históricos de influência em uma mesma região, ou país, geram contextos vulneráveis comuns que podem afetar distintos territórios, estabelecendo ligações entre populações expostas aos riscos que trabalham ou vivem em diferentes locais. Do mesmo modo, Veyret (2007) acredita que os riscos ambientais resultam da associação entre os riscos naturais e os riscos decorrentes de processos naturais agravados pela atividade humana, sobretudo para atender aos interesses de uma minoria pela ocupação do território.

Nesse contexto, é inegável considerar que o sistema capitalista ao exacerbar a separação do homem da natureza, em seu processo de produção/reprodução, impõe que o ritmo da sociedade não seja mais o ritmo da natureza, mas o ritmo do próprio capital, além de contribuir para intensificação das desigualdades socioeconômicas entre as populações submetidas à vulnerabilidade, à dominação, à exploração por grupos poderosos e, consequentemente, aos riscos ambientais.

A maneira impositiva com a qual, em nome do desenvolvimento, grupos econômicos vêm expropriando os territórios de comunidades tradicionais coloca na ordem do dia o debate entre vulnerabilidade e desterritorialização. Seja com a expulsão, ou perda da autonomia territorial, a vulnerabilidade dessas populações perante os grandes projetos econômicos exprime a perda da cidadania, a deteriorização da saúde, da qualidade de vida, da renda, de bens materiais e imateriais que são referências e suporte à organização e continuidade de suas comunidades. 
Dessa forma, Marandola Jr (2009) observa que a análise multidimensional da vulnerabilidade nos coloca que riscos semelhantes, impactos e perigos iguais atingem lugares e populações distintamente. Assim, não nos parece novidade afirmar, portanto, que a distribuição dos riscos da modernidade não seria tão democrática, como defende Beck (2006), uma vez que esses atingem, em primeira instância, os grupos sociais mais vulneráveis do ponto de vista das relações de poder e renda. Nesse caso, apesar de existir um entendimento de que a condição de vulnerabilidade é inespecífica, ou seja, todos estão expostos às situações de vulnerabilidade e risco, ela, também, deve ser compreendida enquanto assimétrica, pois as pessoas não são afetadas da mesma maneira, grau e intensidade. Portanto, aqueles que têm maior poder de proteção conseguem, via mobilidade espacial, influenciar nos processos decisórios, de localizações dos empreendimentos, etc., livrar-se de situações de agravo, enquanto que os que estão fora desse circuito terão sua mobilidade restrita (ACSELRAD, 2006) ou, ainda, sua desterritorialização acentuada.

Essa compreensão deve ser estendida, principalmente, aos casos em que esse problema é produto, não das condições naturais ou contextuais, mas, sobretudo de questões situacionais, ou seja, aquela produzida. Entendemos essa última como produzida por condições sociais e ambientais adversas resultantes de impactos promovidos por terceiros e que alteram as qualidades e as bases de segurança que alicerçavam o cotidiano de um determinado grupo. Nessa perspectiva, o que estaria em jogo não seria a condição de destituídos da capacidade de se defender, mas os mecanismos que condicionam a vulnerabilidade dos sujeitos (ACSELRAD, 2006).

Acselrad $(2006$, p. 2) propõe, nesse sentido, que os vulneráveis sejam analisados como vítimas de uma proteção desigual e aponta o "foco no déficit de responsabilidade do Estado e não no déficit de capacidade de defesa dos sujeitos". Tal posição desloca o debate sobre vulnerabilidade da identificação das incapacidades para a proteção dos vulneráveis remetendo as atenções para a distribuição desigual da proteção, sobretudo quando o próprio Estado se coloca como causador das situações de agravo.

Se a exposição a determinados agravos, a riscos e a consequente vulnerabilidade dos sujeitos não podem ser entendidas enquanto simples incapacidade que populações, indivíduos ou grupos têm para responder 
positivamente à ocorrência de adversidades sociais e ambientais, esse fenômeno necessita ser problematizado pela crítica a um sistema de garantia de direitos em que o Estado deveria ser o provedor da proteção dos sujeitos e não pela incapacidade dos atingidos em reagir diante de situações que lhes são impostas.

Se observarmos por esse ângulo, a análise da vulnerabilidade deve ser realizada invertendo a culpabilização das populações que se veem expostas a determinados agravos pela crítica a um sistema de garantias sociais que deveriam funcionar como mecanismo de proteção para que os cidadãos, quando submetidos a determinadas eventualidades, pudessem responder a elas tendo por base um sistema que funcionasse como inibidor ou atenuador das situações que nos coloca em perigo. Dito dessa forma, a vulnerabilidade deve ser problematiza pela crítica à produção da desigualdade social que se reproduz em outras instâncias e contingências da vida social e pela ausência de um sistema de proteção social no plano de sua efetiva garantia e promoção.

\section{AS PRÁTICAS DE APROPRIAÇÃO DO TERRITÓRIO E A PRODUÇÃO DA IN- JUSTIÇA AMBIENTAL}

Sob a ótica das desigualdades, as práticas sociais de apropriação territorial nos fornecem um elenco de situações nas quais é possível constatar o modo com que um território é constantemente construído e reconstruído. Nesse processo, destacam-se as forças e interesses com as quais o capital intensifica as transformações que se produzem no espaço, a ponto de torná-lo viável às suas iniciativas e operações, tornando sem irrelevância a presença, a história e um sistema de representação que grupos, social e politicamente desprovidos de força na estrutura de poder têm na organização desse espaço, reforçando assim uma apropriação desigual do território que se executa com base nas condições desiguais da distribuição do poder.

É ao tornar, portanto, o espaço que se transforma em um território de interesses que se sobrepõem às vontades e expectativas de grupos desprovidos socialmente de poder que se constrói nas mais variadas regiões do Brasil um processo de segregação espacial com graves efeitos e repercussões sobre o tecido social das 
camadas mais pobres e, no mesmo grau, sobre os recursos ambientais dos espaços apropriados pelo capital. Essa apropriação ocorre por meio de uma dinâmica de valorização e importância estratégica conferida pelo discurso de desenvolvimento do mercado, fazendo com que as forças produtivas exerçam uma maior pressão para que o meio ambiente seja transformado.

Nesse caso, locais que historicamente se apresentavam como desprovidos de quaisquer interesses, ou protegidos (por leis ambientais) do desejo voraz do modelo hegemônico de desenvolvimento, têm, atualmente, sucumbidos aos projetos de crescimento econômico que voluntariamente preocupam-se apenas com as necessidades de reprodução do grande capital e da ampliação das taxas de lucros das empresas. É assim que a legislação ambiental é negligenciada e códigos de regulação são revistos em uma tentativa coordenada de alterar as barreiras institucionais e circunstanciais que se colocam como comprometedoras de tais iniciativas. O novo código florestal se constitui nesse sentido, a matéria-prima de um conjunto de intenções que colocam a revisão e a flexibilização das leis ambientais não enquanto barreiras, mas como um aporte à expansão da fronteira agrícola e dos espaços de mineração em direção de territórios indígenas, de quilombolas e de áreas de conservação ambiental.

Se atualmente, de um lado, as reservas ambientais representadas por sua capacidade de produzir amenidades, sejam nos espaços rurais ou urbanos, restringem-se cada vez mais ao bem-estar de uma minoria privilegiada, de outro lado se desqualificam determinados territórios processando uma conversão dos recursos de uso comum as intencionalidades do privatismo que fazem do mercado a medida de todas as coisas. A flexibilização das leis ambientais, ou seu negligenciamento, nos projetos econômicos conduz ao cerceamento dos direitos territoriais de povos indígenas e comunidades tradicionais localizadas em áreas de conservação ambiental, como ocorreu com a revisão, por exemplo, de vários códigos que disciplinam a vida social como é o caso do código florestal brasileiro. Essa flexibilização tende a favorecer a expansão do agronegócio e da mineração nas diversas fronteiras agromineradoras espalhadas pelo Brasil afora, gerando determinados tipos de empregos - inclusive o precarizado, a um custo ambiental e social sem precedentes na história atual de nosso país. 
Dito dessa forma, entende-se que as práticas de apropriação do território feitas por grupos empresariais, como do setor de minérios e do agronegócio, por exemplo, contribuem para a expropriação de comunidades inteiras que ao perderem a autonomia sobre os espaços onde habitavam perdem, também, os direitos e os sentidos que orientam as suas vidas, tornando-se cada vez mais dependentes e excluídos por um modelo de desenvolvimento orientado sobre lógicas totalmente distintas às formas de organização e reprodução social que construíram (Verticalidade e Horizontalidade, SANTOS, 2001).

A desterritorialização dessas comunidades expressa mais uma problemática da questão socioambiental de nosso tempo - a injustiça ambiental, embora essa prática possa ser encontrada nas mais pretéritas sociedades (ACSELRAD, 2004b), sua permanência torna a atualidade desse fenômeno uma necessidade mais que urgente para proposição de novos parâmetros não apenas para nossa relação com a natureza, mas, sobretudo para com as relações entre nós mesmos.

As práticas de injustiça ambiental refletem uma página da história ambiental em que a distribuição desigual dos benefícios e a destinação localizada dos agravos ambientais ocorrem como resultado de políticas públicas e ações privadas que reproduzem as desigualdades sociais no campo ambiental para os grupos com menor poder de se fazerem ouvir e situados em uma escala desigual na estrutura social das decisões e definição das políticas ambientais. Desse modo, "a desigualdade ambiental pode manifestar-se tanto sob a forma de proteção ambiental desigual como do acesso desigual aos recursos ambientais" (ACSERALD; MELLO; BEZERRA, 2009, p. 73).

A temática da injustiça ambiental nos remete, ainda, à preocupação e manutenção de espaços que foram conquistados por um processo contínuo de lutas sociais, a exemplo de áreas de reforma agrária que passíveis da pressão realizada pelo agronegócio, ou por políticas públicas, encontram ameaçada a permanência das populações que ocuparam as terras com o intuito de torná-las um lugar de moradia e de trabalho.

A desterritorialização se expressa como um dos componentes das práticas de injustiça ambiental ao tornar explícito o deslocamento populacional daqueles que preteritamente se instalaram em um espaço e constituíram nele um território. 
Refletindo sobre a desterritorialização na obra de Deleuze, Guattari, Haesbaert e Bruce (2002, p. 01), apontam que "o problema concreto que se coloca é o de como se dá a construção e a destruição ou abandono dos territórios humanos, quais são os seus componentes, seus agenciamentos, suas intensidades".

Nesse sentido, enquanto recorte das práticas da injustiça ambiental a desterritorialização deve ser concebida como processo que pressiona pela expulsão de populações tradicionais de seus territórios ancestrais ou dos locais de pertencimento que produzem nos sujeitos os sentidos de coesão e solidariedade social deixando-os à deriva de suas referências espaciais, marginalizando-os e pauperizando-as em relação às condições materiais que antes viviam.

As estratégias nas quais essas práticas se inserem revertem-se na desqualificação dos locais de trabalho (degradado, monótono, revogável e das condições em que se realiza o trabalho) na redução ou na destruição das amenidades ambientais (tais como ar puro, áreas verdes e água limpa) e pressionam para que as populações locais percam a autonomia sobre o território. Verifica-se, ainda, uma constância nessas estratégias em relação às decisões locacionais de empreendimentos perigosos, produtores de poluição ambiental e que colocam em situação de risco a integridade e a saúde de grupos fragilizados do ponto de vista social.

Entretanto, o fenômeno aqui analisado não se restringe à passividade dos sujeitos que são atingidos por este processo, ao contrário, as tramas territoriais envolvem, por outro lado, a capacidade de reação e resistência das populações atingidas por interesses privados que procuram desterritorializá-los.

\section{A LUTA POR JUSTIÇA AMBIENTAL: FORMAS REATIVAS DE RESPONDER A VULNERABILIDADE CONSTRUÍDA PELA DESTERRITORIALIZAÇÃO}

Apesar das populações atingidas por grandes e médios empreendimentos se sentirem acuadas diante de projetos que por possuírem grande poder econômico e influência política investem na desterritorialização de seus babitats, várias formas de organização e experiências de luta vêm sendo construídas no processo de deslegitimação socioambiental desses projetos. 
As estratégias elaboradas por essas populações e pelas organizações que buscam apoiá-las procuram, em primeiro plano, construir um argumento científico que se contraponha às justificativas e parâmetros criados pelos empreendedores e que tornam a obra um projeto inquestionável. A intenção nessa forma de embate é estabelecer elementos que se situem no mesmo plano argumentativo de forma que a posição assumida pelos atingidos não seja desconsiderada pela justiça por julgá-la fundada em um discurso leigo e, portanto, descaracterizado da técnica necessária à avaliação do conhecimento perito.

No segundo plano, procura-se constituir ações que promovam o adiamento do início das obras, ou a sua paralisação, seja por meio de piquetes, passeatas ou denúncias feitas através da mídia, seja com abertura de processos na instância jurídica com o intuito de apresentar como ilegal o desenvolvimento daquela atividade. As duas formas estratégicas de mobilização dos atingidos se situam no que Acselrad (2004b, p. 29) define como ação coletiva dirigida contra a ordem ambiental tida por injusta e se encontra situada em dois planos - um objetivista e outro discursivo. $\mathrm{O}$ primeiro conformaria ações que compreendem o "espaço de distribuição do poder sobre as coisas", ou seja, o avanço na disposição prática ao enfrentamento dos problemas ocasionados por danos ambientais, por exemplo. No segundo, ocorre a pressão no "espaço na esfera pública como estratégia discursiva de aplicação dos dispositivos legais".

Nesse sentido, vários movimentos sociais, no Brasil, procuram usar tais estratégias para consecução dos seus objetivos e, dentre eles, pode-se citar o MST - Movimento de Trabalhadores Rurais Sem Terra, a Rede Brasileira de Justiça Ambiental, o MAB - Movimento de Atingidos por Barragens. O MST tem investido em ocupações de terras como forma de pressionar a realização da reforma agrária, a distribuição justa das terras e o questionamento aos transgênicos. Já a Rede de Justiça Ambiental "constituiu-se como um fórum de discussões, de denúncias, de mobilizações estratégicas e de articulação política, com o objetivo de formulação de alternativas e potencialização das ações de resistência desenvolvidas por seus membros - movimentos sociais, entidades ambientalistas, ONGs, associações de moradores, sindicatos, pesquisadores universitários e núcleos de instituições de pesquisa/ensino" (www.justicaambiental.org.br). 
Por fim, o MAB tem procurado questionar a política energética nacional e a construção de barragens como uma forma de violação dos direitos humanos. A esse respeito, os efeitos da desterritorialização enquanto produtores de vulnerabilidades são evidenciados pelo claro rebatimento sobre a vida das mulheres atingidas por barragens. Segundo o MAB (2011) as principais violações dos direitos das mulheres são: a) agravamento das condições de trabalho, b) não reconhecimento do trabalho doméstico e do campo, c) perda do trabalho gerador de renda, d) não adaptação ao trabalho urbano, e) coação de funcionários das construtoras, f) prostituição, g) perda dos vínculos comunitários, h) quebra de laços familiares.

Um elenco de estratégias situadas no âmbito do plano objetivista e discursivo pode ser assim expresso, tomando como base as ações da Rede de Justiça Ambiental no Brasil, segundo Acselrad, Mello e Bezerra (2009): a) a produção de conhecimento próprio para realizar a avaliação de equidade ambiental como forma de contrapor o atual modelo de avaliação presente nos Estudos de Impacto Ambiental (EIA); b) Pressão pela aplicação e aperfeiçoamento de leis universais fazendo com que a legislação existente seja utilizada sem que o aparato estatal crie um padrão de permissividade para ambiental com relação, principalmente, ao licenciamento ambiental; c) Pressão por novas racionalidades no exercício estatal para que a intervenção tecnicista sobre o meio ambiente seja substituída ou incluída as "variáveis sociais e culturais no gerenciamento do risco ambiental"; d) Produção de novas metodologias da equidade ambiental tendo em vista que o modelo de avaliação do impacto ambiental tem sido incapaz de retratar a injustiça ambiental dos grandes projetos; e) Ação direta, responsável pela ocupação de canteiros de obras, paralisação de estradas como forma de questionar a pertinência de determinados empreendimentos; e, por último, f) A difusão espacial do movimento que compreende o fato de que as ações de injustiça ambiental não se restringem a uma determinada população ou região do globo.

Atualmente, tem se processado uma nova estratégia de ação que invoca a produção de mapas distintos do mapeamento estatal ou privado do território retirando do Estado "o monopólio da representação territorial de modo a contestar seu protagonismo na produção de uma cartografia que é funcional ao modelo hegemônico de desenvolvimento capitalista" (ACSELRAD, 2010, p. 05). O chamado mapeamento participativo corresponde assim à produção de 
conhecimentos constituídos pelas populações atingidas por políticas ambientais e por empreendimentos públicos e privados que provocam a expulsão e desterritorialização de comunidades. Projeta-se, dessa forma, uma cartografia que se situa para além dos pressupostos de uma ciência geográfica tradicional e se coloca como um "instrumento de contramapeamento utilizado para se evidenciar a diversidade da paisagem rural e dos direitos costumeiros destinados a proteger territórios indígenas do avanço das monoculturas [...]" (ACSELRAD, 2010, p. 13).

Como se observa o processo de desterritorialização de populações tradicionais e pobres é um dos aspectos em que se insere o debate sobre as questões socioambientais de nossa época. Nesse fenômeno se encontra uma produção de vulnerabilidades, consequência direta da desterritorialização dessas populações como o que ocorre com a expulsão de comunidades indígenas, quilombolas, ribeirinhas e seringueiras que ao perderem a autonomia sobre seu território perdem as referências sociais e culturais de seu mundo, presenciam um processo intenso de precarização do trabalho, destruição dos recursos ambientais com que mantinham uma relação direta e a perda dos vínculos de solidariedade e padrões de sociabilidade que orientam suas vidas.

\section{REFERÊNCIAS}

ACSELRAD, H. As práticas espaciais e o campo dos conflitos ambientais. In: ACSELRAD, Henri (Org). Conflitos ambientais no Brasil. Rio de Janeiro: Relume Dumará; Fundação Heinrich Böll, 2004.

ACSELRAD, H. Justiça ambiental: ação coletiva e estratégias argumentativas. In: ACSELRAD, H.; HEERCULANO, S.; PÁDUA, J. A. Justiça ambiental e cidadania. Rio de Janeiro: Relume Dumará; Fundação Ford, 2004b.

ACSELRAD, H. Vulnerabilidade ambiental, processos e relações. In: ENCONTRO NACIONAL DE PRODUTORES E USUÁRIOS DE INFORMAÇÕES SOCIAIS, ECONÔMICAS E TERRITORIAIS, FIBGE, Rio de Janeiro, 2006. Anais eletrônicos... Disponível em: <http://www.fase.org.br/projetos/clientes/noar/noar/UserFiles/17/ File/VulnerabilidadeAmbProcRelAcselrad.pdf $>$ Acesso em: 13 fev. 2010. 
ACSELRAD, H.; MELLO, C. C. A.; BEZERRA, G. N. O que é justiça ambiental. Rio de Janeiro: Garamond, 2009.

ACSELRAD, H. Prefácio. In: ACSELRAD, H. Cartografia social e dinâmicas territoriais: marcos para o debate. Rio de Janeiro: IPUR/UFRJ, 2010.

BECK, U. La sociedad del riesgo: hacia una nueva modernidad. Barcelona: Paidós, 2006.

FERNANDES, J. L. J. Implantação de projectos de desenvolvimento, desterritorialização e vulnerabilidade das populações: o caso da construção de barragens. In: ENCUENTRO INTERNACIONAL SOBRE POBREZA, CONVERGENCIA Y DESARROLLO, 4., 2008. Anais... Universidad de Málaga, 2008. 1 CD-ROM.

HAESBAERT, R. O Mito da Desterritorialização: do fim dos territórios à multiterritorialidade. Rio de Janeiro: Bertrand Brasil, 2004.

HAESBAERT, R. Territórios alternativos. Niterói: Contexto, 2002.

HAESBAERT, R.; BRUCE, G. A Desterritorialização na obra de Deleuze e Guattari. Geographia, Niterói, v. 7, p. 2, 2002. Disponível em: < http://www.uff.br/geographia/ ojs/index.php/geographia/article/view/74> . Acesso em: 09 out. 2011.

HERCULANO, S. Desastres ambientais, vulnerabilidade social e pobreza. Revista Novamerica, Rio de Janeiro, v. n. 111, 2006. Disponível em: < http://www. novamerica.org.br/revista_digital/L0111/rev_emrede.asp > . Acesso em: 13 fev. 2008.

LEITE LOPES, J. S. et al. A ambientalização dos conflitos sociais: participação e controle público da poluição industrial. Rio de Janeiro: Relume Dumará; Núcleo de Antropologia da Política/UFRJ, 2004.

MAB - Movimento de Atingidos por Barragens. $O$ modelo energético e a violação dos direitos humanos na vida das mulheres atingidas por barragens. Disponível em: <http://www.mabnacional.org.br/> . Acesso em: 12 out. 2011.

MARANDOLA Jr., E. Tangenciando a vulnerabilidade. In: HOGAN, D J; MARANDOLA Jr., E (Org.). População e mudança climática: dimensões humanas das mudanças ambientais globais. Campinas: UNICAMP; Brasília; UNFPA, 2009. 
MELUCCI, A. Challenging codes: collective action in the information age. Cambridge: Cambridge University Press, 1996.

PORTO, M. F. S. Uma ecologia política dos riscos: princípios para integrarmos o local e o global na promoção da saúde e da justiça ambiental. Rio de Janeiro: FIOCRUZ, 2007.

RIBEIRO, A. C. T. Outros territórios, outros mapas. In: OSAL: Observatório Social de América Latina, Buenos Aires, v. 6, n. 16, jun. 2005. Disponível em: <http:// bibliotecavirtual.clacso.org.ar/ar/libros/osal/osal16/D16TRibeiro.pdf $>$. Acesso em: dez. 2015.

SANTOS, M. O retorno do Território. In: SANTOS, M. et al. (Org.). Território: globalização e fragmentação. 4. ed. São Paulo: Hucitec; Anpur, 1998. p. 15-20.

SANTOS, M. Território e sociedade: entrevista com Milton Santos. 2. ed. São Paulo: Fundação Perseu Abramo, 2000.

SANTOS, M. Por uma outra globalização: do pensamento único à consciência universal. Rio de Janeiro: Record, 2001.

SOUZA, E. A.; PEDRON, N. R.. Território e identidade. Revista Eletrônica da Associação dos Geógrafos Brasileiros, v. 1, n. 6, ano 4, nov. 2007. Disponível em: <http://www.ceul.ufms.br/revista-geo/artigo6_EdevaldoS._e_NelsonP..pdf > . Acesso em: 26 ago. 2011.

TUAN, Y.-F. Espaço e lugar: a expectativa da experiência. São Paulo: DIFEL, 1983.

VEYRET, I. Os riscos: o homem como agressor e vítima do meio ambiente. São Paulo: Contexto, 2007.

Recebido em: 23 de junbo de 2015 Aceito em: 21 de janeiro de 2016 